\title{
New Perspectives for the Use of Potentilla alba Rhizomes to Treat Thyroid Gland Impairments
}

\author{
Authors \\ Affiliations \\ 1 Department of Pharmacognosy, Faculty of Pharmacy with \\ the Division of Laboratory Medicine, Medical University of \\ Białystok, Białystok, Poland \\ 2 Student's Scientific Association, Department of Pharma- \\ cognosy, Medical University of Białystok, Białystok, Poland \\ 3 Warägerweg 21, Berlin, Germany \\ Key words \\ Potentilla alba, Rosaceae, phytochemical profile, \\ pharmacology, thyrotropic activity \\ received \\ accepted after revision \\ published online \\ July 28,2021 \\ September 27, 2021 \\ October 29, 2021 \\ Bibliography \\ Planta Med 2023; 89: 19-29 \\ DOI 10.1055/a-1663-6461 \\ ISSN 0032-0943 \\ (c) 2021. Thieme. All rights reserved. \\ Georg Thieme Verlag KG, Rüdigerstraße 14, \\ 70469 Stuttgart, Germany
}

Daniel Augustynowicz ${ }^{1}$, Magdalena Podolak ${ }^{2}$, Klaus Peter Latté ${ }^{3}$, Michał Tomczyk ${ }^{1}$

Correspondence

Michał Tomczyk, PhD

Department of Pharmacognosy, Faculty of Pharmacy

with the Division of Laboratory Medicine, Medical University

of Białystok

ul. Mickiewicza 2a, 15-230 Białystok, Poland

Phone: + 48857485694 , Fax: + 48857485614

michal.tomczyk@umb.edu.pl

\section{ABSTRACT}

Potentilla alba is a valuable medicinal plant that has been highly praised even before its first appearance in herbal books; however, it has now been forgotten in Western Europe. Currently, this species is used in Eastern Europe as a remedy to treat dysentery and various thyroid gland dysfunctions. The present review summarizes the advances in the phytochemical, pharmacological, and toxicological research related to this plant species. Clinical trials that have been conducted to date support its traditional use for treating thyroid disorders, although its exact mechanism of action, bioavailability, and pharmacokinetics data are missing.

\section{Introduction}

Plant-derived drugs and dietary supplements are gradually emerging as alternatives to treat health problems, mainly due to the reduced number of side effects compared with classical therapy $[1,2]$. Although there are a significant number of reports concerning the traditional uses of plant species, there is an urgent need to evaluate plant-derived medications true clinical outcomes, their interactions with prescription medications, and long-term safety in vitro, in vivo, and in clinical studies [3,4].

Potentilla alba L. (Rosaceae) has a long tradition of therapeutic use in Europe, especially in the eastern part of the continent. Mainly, the rhizome of this plant have been used alone or as a part of a comprehensive therapy to treat thyroid gland disorders [5, 6]. Despite the great potential that has been revealed in several clinical studies conducted in Ukraine and the availability of methods enabling solid dosage form production with the white cinquefoil extract that complies with Russian Pharmacopeia requirements [7], there has been no herbal drug approved by the European Union that contains $P$. alba. However, a few dietary supplements imported from Eastern Europe containing $P$. alba rhizome extract are slowly becoming more popular in the European Union's pharmacies and online markets. Thus, there is still a need for further evaluation and standardization of such supplements. Moreover, further assessment is required to identify the main components responsible for the observed effects. This review therefore aims to examine and discuss the literature data concerning the biological and pharmacological aspects of $P$. alba preparations.

\section{Methodology/Methods Search}

All relevant information concerning the botanical description, traditional use, phytochemical composition, pharmacological activities, and toxicological aspects of $P$. alba was collected from published literature, with no time restrictions. The electronic databases used for the data collection included EBSCO, EMBASE, Google Scholar, PubMed, REAXYS, ScienceDirect, Scopus, Springer Link, Taylor \& Francis, and Web of Science using the terms "Potentilla" and/or "Potentilla alba" and/or "white cinquefoil" and/or "Rosaceae" and/or "botanical description" and/or "alba" and/or "herb extract" and/or "root extract" and/or "ethnopharmacology" and/or "phytochemistry" and/or "antibacterial ac- 
tivity" and/or "antiviral activity" and/or "antioxidant activity" and/ or "adaptogenic activity" and/or "anti-neoplastic activity" and/or "thyrotropic activity" and/or "thyroid treatment" and/or "toxicity". Moreover, books, conference papers, and PhD theses were studied for relevant information.

\section{Inclusion and exclusion criteria}

Relevant articles in all languages were identified and independently evaluated for their competence and inclusion by two different authors. After compliance with the inclusion criteria, experimental research and clinical trials that assessed the target plant composition and/or evaluated its effects were included in this research. Improper studies (1), original papers considering only other species from the genus Potentilla (2), or articles with a lack of access to the abstract and/or main text (3) were excluded.

\section{Botanical Description and Distribution}

P. alba, also known as white cinquefoil, is one of approximately 500 species of the genus Potentilla belonging to the Rosaceae family. The valid taxonomic name of this species was first described in 1753 by the Swedish botanist Carl von Linné in his work "Species Plantarum" [8]. This Potentilla species is also known under the synonyms of Dasiphora alba (L.) Raf., Fragaria alba (L.) Crantz., Fragariastrum album (L.) Schur, P. alba f. obovata (Th.Wolf) Diklic, Potentilla nitida Scop., and Trichothalamus albus (L.) Fourr. [9].

P. alba is distributed in the central parts of Europe and West Asia in temperate and subarctic climatic zones. Thus, this species is indigenous to France in the western part of Europe to the central and southern parts of Russia in the east and from the Baltic states, Poland, and Germany southwards to Italy, Albania, and Romania. This plant has also been introduced to Great Britain [9]. $P$. alba is widely distributed in a variety of environments, including deciduous forests, where it is a characteristic species for the plant community of the dry-mesic oak forest Potentillo albae-Quercetum petraeae, as well as grasslands, heaths, and alpine slopes $[10,11]$. However, the extensive demand of white cinquefoil rhizomes for medical purposes threatens this species, causing it to be endangered or close to depleted in natural habitats $[12,13]$.

The plant is a vigorous herbaceous perennial $8-25 \mathrm{~cm}$ high with a $35-\mathrm{cm}$ long, oblique, stout, and dun rootstock, i.e., roots and rhizomes. Rising stalks are often loosely bent and surmounted by a rosette of leaves. Basal leaves are long stalked and palmate with 5 leaflets, while stem leaves are alternate with 3 leaflets and short stalked or stalkless. Leaflets have a lanceolate obovate shape, toothed at the apex, and silky hair covering underneath. The stipules are usually smaller and red-yellow colored. Notably, the plant creates 1 to 5 individual flowers occurring in spring, which, in contrast to most Potentilla species, possess five obovate white-colored petals. Moreover, the stamens with white filaments occur in the number of 20 . There are 5 silvery hairy sepals and a 5-sectioned epicalyx. The fruit takes the form of matt and lightly ridged achene $[10,14,15]$.

\section{Traditional Use}

Potentilla species have been used in medicine since antiquity [5]. Before the introduction of the modern taxonomy by Linné in 1753, P. alba was known as Quinquefolium album and Pentaphyllum album [8]. The first report treating P. alba use dates from 1543 in a New Kreüterbuch book by Leonhard Fuchs. One of the species described and depicted in the chapter "Fünffingerkraut" was white cinquefoil ("Groß Weiss Fünffingerkraut"), of which the underground parts were used externally to treat inflammation of the mouth and throat and toothache. Internal use described for the underground parts included the treatment of dysentery, ulcers, and jaundice. Aerial part application included the treatment of fever, jaundice, fistula, and as an astringent [16]. P. alba was also mentioned in the herbal book Tabernaemontanus dating from 1588, with similar indications for use [17]. Since the 18th century, in Eastern Europe and particularly in Belarusian Polesie, there has been a common practice of using $P$. alba decoctions as a substitute for Camellia sinensis [18].

White cinquefoil is traditionally used in Eastern Europe to treat diseases of the liver, cardiovascular system, and gastrointestinal tract and as a wound healing agent due to its antibacterial activity. Extracts from the aerial parts stimulate the central nervous system, whereas the underground parts of this plant increase diuresis, enhance bile secretion, and improve intestinal function. In folk medicine, an infusion of $P$. alba roots is prepared for painful menstruation as an antispastic and analgesic agent. A decoction of the roots with rhizomes is used for gout, rheumatism, jaundice, and dysentery. In folk medicine of Belarus, it is recommended to drink a decoction of the aerial parts of white cinquefoil when suffering from prolapse of the uterus $[19,20]$.

Currently, the use of an infusion of the underground parts to treat hypo- and hyperthyroidism has been reported as a standard therapy, especially in Ukraine, Belarus, and the Federation [13, 21]. Moreover, phytotherapists in post-Soviet states, especially Russia, recommend $P$. alba as an adaptogen, a treatment for heart diseases, or as a psychostimulant of the central nervous system [22]. However, the only species from the genus Potentilla included in the latest Russian Pharmacopoeia is the Potentilla erecta rhizome [23].

\section{Chemical Constituents of Potentilla alba}

A number of studies have confirmed the occurrence of at least 47 compounds for the rhizomes and/or aerial parts of $P$. alba that have been isolated or detected and completely identified with the use of chromatographic and spectral methods.

A predominant group of constituents from the underground parts are condensed tannins, with a total procyanidin content estimated to be $7.3 \%$ of the raw material dry mass. However, the authors of this study did not detect hydrolysable tannins in $P$. alba rhizomes $[24,25]$. Only ellagic acid, as a degradation product of ellagitannins, was identified, apart from gallic acid, a precursor of hydrolysable tannins [26]. In addition to the precursors of condensed tannins (+)-catechin and (-)-epicatechin and their 4-benzyl thioether derivatives, a series of oligomeric procyanidines have been isolated and elucidated [27]. Additionally, two flavonoid 
aglycones and three flavonoid O-glucosides were identified [26]. Furthermore, from a chemophenetic point of view, the presence of tormentic acid ( $\bullet$ Fig. 1 ) in the subterranean parts of $P$. alba confirms the general chemical homogeneity in the genus Potentilla. Moreover, underground parts are rich in fatty acids, polysaccharides, amino acids, and macro- and microelements such as calcium, magnesium, iron, phosphorus, potassium, manganese, and iodine [28].

Several phytochemical studies have been performed with the aerial parts of $P$. alba and at least 29 compounds were completely identified. The dominant group of compounds were flavonoids, with five compounds identified as flavonoid aglycones and nine as flavonoid $\mathrm{O}$-glycosides, which are generally quercetin and kaempferol glycosides. Moreover, several structures of $\mathrm{O}$-glycosides have not been completely elucidated. Further ingredients include phenol carboxylic acids, mainly structural isomers of caffeoylquinic and coumaroylquinic acids. Additionally, the structures of dimeric and trimeric type B proanthocyanidins were elucidated from the aerial parts of the plant, connected by 4,8 bonds, such as procyanidin B1, procyanidin B2, and trimeric procyanidin $C 1$. The structures of selected procyanidins are presented in $>$ Fig. 2. More interestingly, in the leaves of $P$. alba, catechin, a precursor for proanthocyanidins, was not detected [29], while in a recent work, catechin was present in whole aerial part preparations [30]. Previously, (-)-epicatechin was isolated from the leaves of white cinquefoil [19]. The current status of the phytochemical constituents of $P$. alba is summarized in > Table 1.

Due to the limited natural reserves of $P$. alba, there have been attempts to develop a method allowing the production of the plant using a hydroponics technique with clonal micropropagation. This method may lead to the accumulation of elements from the nutrient media in plant organs similar to intact plants. Although the obtained results are promising, there is still an advantage to using intact plants when considering the content of secondary metabolites [31, 42]. Researchers in Pyatigorsk (Russia) in the Northern Caucasus worked on recommendations for the conventional cultivation of $P$. alba. The most convenient method of white cinquefoil reproduction was the division of the rhizomes into cuttings. Based on the observations of a 3-year project, the authors concluded that during the first 5 years of life, active plant

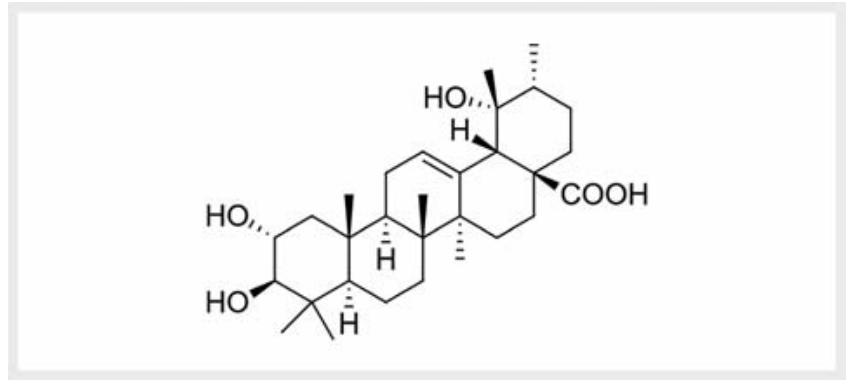

- Fig. 1 Structure of tormentic acid.

growth and an increase in biomass are noted. By the 5th year of life, the rhizomes are fully formed and suitable for pharmaceutical use [43]. In another approach, reported from a great $P$. alba plantation in the Bryansk region (Russia), shoot buds with a piece of the root and two to four leaves were separated manually from the mother plant for plant propagation [44].

\section{Pharmacological Profile}

Preparations based on the aerial part of $P$. alba have less pharmacological activity than the roots and rhizomes of this plant [19]. In addition to the in vitro and few in vivo studies, a number of publications address clinical studies of rhizome extracts for the treatment of thyroid gland impairments. An overview of the current status of pharmacological evaluations of $P$. alba is outlined in > Table 2.

\section{In vitro studies}

\section{Antioxidative activity}

The radical scavenging properties were verified for the aerial and underground parts. The abundance of polyphenols, such as flavonoids and procyanidins, present in the species exerts a protective effect against oxidative damage. A few reports have uncovered high antioxidant properties of various extracts from the herbal parts measured by 1,1-diphenyl-2-picrylhydrazyl (DPPH), ferric reducing antioxidant power (FRAP), and ferrous ion chelating (FIP) assays [29,30]. Similar significant antioxidant activity, with the assignment of additional assays, such as N,N-dimethyl-p-phe-<smiles>Oc1cc(O)c2c(c1)O[C@H](c1ccc(O)c(O)c1)[C@H](O)[C@H]2c1c(O)cc(O)c2c1O[C@H](c1ccc(O)c(O)c1)[C@H](O)C2</smiles>

procyanidin B1<smiles>Oc1cc(O)c2c(c1)O[C@H](c1ccc(O)c(O)c1)[C@H](O)C2c1c(O)cc(O)c2c1O[C@H](c1ccc(O)c(O)c1)[C@H](O)C2c1c(O)cc(O)c2c1O[C@H](c1ccc(O)c(O)c1)[C@H](O)C2</smiles>

procyanidin $\mathrm{Cl}$

- Fig. 2 Structures of selected procyanidins, procyanidin B1 and procyanidin C1. 
- Table 1 Compounds and elements of the underground and aerial parts of $P$. alba L.

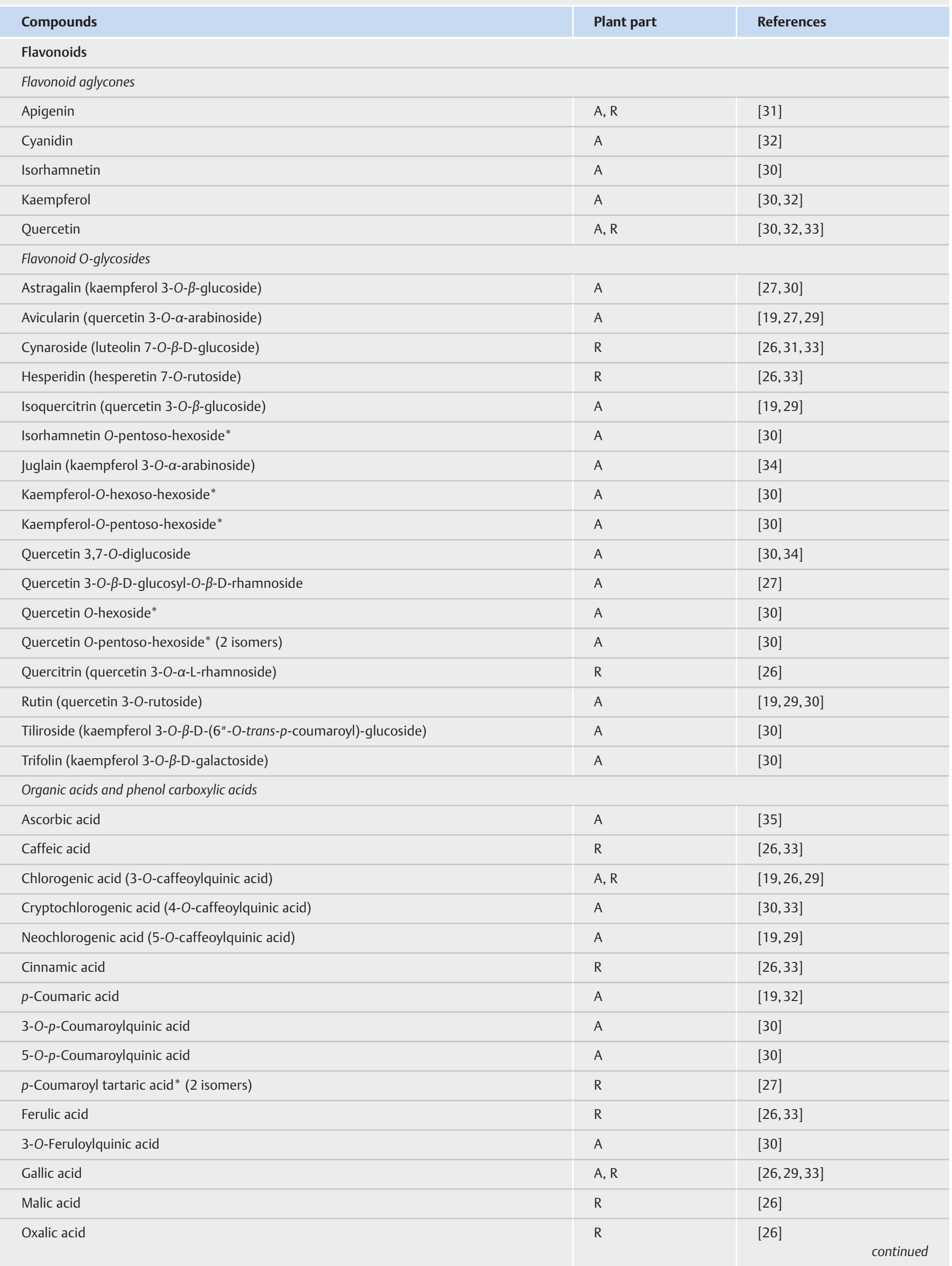


- Table 1 Continued

Compounds

Tannins

Condensed tannins (proanthocyanidins) and their precursors

(-)-Epicatechin

(+)-Epicatechin 4-benzylthioether

(+)-Epicatechin monoglucoside*

(+)-Catechin

(+)-Catechin 4-benzylthioether

(+)-Catechin monoglucoside*

$(+)$-Catechin 3-O- $\beta$-D-glucopyranoside

$(+)$-Catechin 7-O- $\beta$-D-glucopyranoside

Epigallocatechin gallate

Procyanidin B1 (epicatechin-( $4 \beta \rightarrow 8)$-catechin)

Procyanidin B2 (epicatechin-( $4 \beta \rightarrow 8)$-epicatechin)

Procyanidin type B dimer monoglucoside*

Procyanidin type B dimer* (5 isomers)

Procyanidin C1 (epicatechin-( $4 \beta \rightarrow 8)$-epicatechin- $(4 \beta \rightarrow 8)$-epicatechin)

Procyanidin type B trimer* ( 2 isomers)

Procyanidin type $B$ tetramer* (1 isomer)

Procyanidin type B pentamer* ( 3 isomers)

Procyanidin type A dimer* (3 isomers)

Procyanidin type A trimer* ( 4 isomers)

Procyanidin type A tetramer* (4 isomers)

Procyanidin type A pentamer* ( 2 isomers)

Procyanidin type A hexamer* ( 2 isomers)

Hydrolysable tannins and related compounds

Ellagic acid

Gallic acid monoglucoside

Triterpenes

Tormentic acid

Dihydrocoumarin

\section{Others}

Aminoacids

Fatty acids, e.g., palmic, stearic, linoleic, linolenic acid

Polyprenols with $19-45$ units

Polysaccharides

Sitosterol

Sitosterol 3-O- $\beta$-D-glucoside (daucosterol)

Micro- and macroelements, e.g., magnesium, calcium, potassium, iron, manganese, phosphorus, iodine

${ }^{*}$ Structure not fully elucidated; $A$ = aerial part; $R$ = root and/or rhizome
$\mathrm{R}$

[33]

Plant part

References

A, R

$[19,26,27,33,36]$

[36]

[27]

$\mathrm{R}$

$[27,30,37,38]$

A, R

[36]

$\mathrm{R}$

[27]

$\mathrm{R}$

[37]

[37]

$\mathrm{R}$

$[26,33]$

A

$[19,29]$

A

$[19,29]$

R [27]

R [27]

A

$[19,29]$

$\mathrm{R}$

[27]

$\mathrm{R}$

[27]

R

[27]

R

[27]

R

[27]

R

[27]

R

[27]

R

[27]

A, $R$

[26, 32, 33]

$\mathrm{R}$

[27]

R

[37]

R

[28]

A, R

$[39,40]$

A

[41]

R

[28]

R

$[37,80]$

$[37,80]$

$\mathrm{R}$

[28] 
- Table 2 An overview on the current status of pharmacological evaluations of $P$. alba L.

\begin{tabular}{|c|c|c|}
\hline Observed effects & Plant part & References \\
\hline \multicolumn{3}{|l|}{ Effects in vitro } \\
\hline Antioxidative activity & $A, R$ & {$[36,45]$} \\
\hline Antimicrobial activity against various bacterial and fungal strains & $A, R$ & {$[32,46,47,49]$} \\
\hline Antiviral activity against herpes simplex virus type II & R & {$[50]$} \\
\hline Antineoplastic activity against HT-29 human colon cancer & A & [30] \\
\hline \multicolumn{3}{|l|}{ Effects in vivo } \\
\hline Adaptogenic activity & $\mathrm{R}$ & [22] \\
\hline Anti-inflammatory activity & $\mathrm{R}$ & [51] \\
\hline Thyrotropic activity & R & [63-65] \\
\hline \multicolumn{3}{|l|}{ Clinical trials } \\
\hline $\begin{array}{l}\text { Thyrotropic activity: efficacy in the treatment of hypo- and hyperthyroidism, hypothyroic and toxic goiter, } \\
\text { diffuse non-toxic goiter, nodular goiter, and autoimmune thyroiditis }\end{array}$ & $\mathrm{R}$ & [66-73] \\
\hline
\end{tabular}

nylenediamine $\left(\mathrm{DMPD}^{+}\right)$, superoxide radical, and hydroxyl radical assays, was reported for water and methanol extracts obtained from rhizomes and roots of $P$. alba $[36,45]$.

\section{Antimicrobial activity}

On several occasions, antimicrobial activities of rhizome extracts have been reported. Bosnian authors investigated the antimicrobial potential of water, ethanol, acetone, and ethyl acetate extracts against selected bacterial and fungal strains - Staphylococcus aureus ATCC 6538, Bacillus subtilis ATCC 6633, Escherichia coli ATCC 8739, and Candida albicans ATCC 10231. Notably, only an acetone preparation at a $1: 1$ dilution and a water preparation at a 1:10 dilution revealed moderate inhibitory activity against S. aureus, with zone of inhibition values peaking at 13.4 and $11.0 \mathrm{~mm}$, respectively. Moreover, acetone and alcohol samples inhibited the growth of the $E$. coli strain in a manner similar to the reference $2 \%$ tannic acid solution. However, the growth of the $B$. subtilis and C. albicans strains was unaffected by the tested extracts [46]. Interestingly, in comparison to an earlier study, recent results showed that the extracts from $P$. alba root exhibited more substantial antibacterial and antifungal activities against $E$. coli ATCC 25922, S. aureus ATCC 25923, and C. albicans EMTK 34 strains, with zone of inhibition values of $21.0 \pm 1.1,19.0 \pm 1.0$, and $22.0 \pm 1.1 \mathrm{~mm}$, respectively. Additionally, strong antibacterial activity against Proteus vulgaris and Pseudomonas aeruginosa strains (zone of inhibition values of $20.0 \pm 1.0$ and $23.0 \pm 1.2 \mathrm{~mm}$, respectively) was observed [47]. In another study, an aqueous extract of $P$. alba roots $(1: 10)$ was shown to be active against the test strains $P$. aeruginosa, $C$. albicans, and $E$. coli after 2 - to 4-fold dilution, whereas this extract was even more active against S. aureus and Bacillus cereus, i.e., after 16- and 32-fold dilution [37]. However, the differences in the obtained results may be explained by the variation in qualitative and quantitative secondary metabolite composition in the plant tissue and in the type of obtained extracts [48] and perhaps also by the different test strains.
Chitosan is a polycationic polymer and one of the most widespread polysaccharides in nature. It is a waste product from the marine food processing industry. Due to its abundant availability, biocompatibility, biodegradability, and susceptibility to chemical modification, a number of researchers are interested in the production of chitosan-based products and their practical application inter alia in the food industry or medicine. In accordance with these advantages, the antimicrobial effects of $P$. alba herbal decoction with a chitosan-based film-forming composition was investigated. The tested sample revealed no toxicity or hemolytic activity and inhibited $B$. cereus growth, with a zone diameter of $34 \mathrm{~mm}$. The authors concluded that the tested preparation could serve as an excellent and safe remedy to increase the shelf life of plant-derived products [49].

\section{Antiviral activity}

A recent study assessed the antiviral potential of $P$. alba ethanol and water extracts from both intact and regenerative plants against herpes simplex virus type II. The study was carried out in the Vero cell line. It was demonstrated that water extracts from intact and regenerative plants exhibited anti-herpes activity. However, a weaker antiviral effect was observed for the ethanol extracts [50].

\section{Antineoplastic activity}

Patients diagnosed with cancer face a variety of problems connected with chemotherapy treatment and with a decrease in quality of life. Thus, the scientific world has focused on research for safer and more effective remedies to increase patient survivability and comfort. Although digestive tract cancers are very common, they are still a significant portion of the worldwide death toll. Recently, Polish authors assessed the cytotoxic effects of selected extracts and fractions of $P$. alba aerial parts against HT-29 human colon cancer and the CCD 841 CoTr human noncancerous colon epithelial cell line. The study showed that the tested samples af- 
fected the integrity of the tumor cell membranes and decreased their proliferation. In particular, extracts abundant in caffeoylquinic acids displayed the highest antineoplastic activity due to their ability to modulate the cell cycle and thus increase apoptosis. Furthermore, the proliferation of normal colon cells was highly promoted, despite damage to cell membranes in the investigated samples, which mildly affected mitochondrial metabolism [30].

\section{In vivo studies}

Adaptogenic activity

In the scientific literature, there have been only a few in vivo studies. Russian authors, based on the recommendations of phytotherapists [38], examined the adaptogenic influence of the $P$. alba rhizome water extract on mice. The experiment comprised swimming endurance, open-field, and light/dark exploration tests. Interestingly, 1-week oral administration of the investigated extract at doses of 36 and $72 \mathrm{mg} / \mathrm{kg}$ body weight (b. w.) revealed a significant enhancement in the swimming time in a dose-dependent manner. Furthermore, the authors found that high glycogen concentrations in the treated rodents correlated with prolonged swimming time. However, the exact mechanism is unknown and should be investigated in the future, but it may involve the antioxidant properties that can protect against oxidative damage. Additionally, P. alba extracts attenuated anxiety symptoms in light/ dark exploration and open-field tests. Although the tested samples at a dose of $72 \mathrm{mg} / \mathrm{kg}$ b. w. increased the time spent by mice in the light chamber, the effect was not significant. In a separate study, animals treated at a dose of $12 \mathrm{mg} / \mathrm{kg}$ placed in a novel environment expressed a significant increase in head dip frequency and the number of squares crossed in comparison to the control group, as well as a reduction in grooming. These results indicate the anxiolytic potential of $P$. alba rhizome preparations. Nonetheless, further phytochemical and pharmacological research is needed to determine the exact mechanism of action and the main components responsible for the observed effects [22].

\section{Anti-inflammatory activity}

It has been found that administration of the acetone and ethanol extracts from the underground parts of white cinquefoil reduced the inflammation process in a mouse ear test model. Inflammation was induced by administration of a $3 \%$ Crotonis oleum acetone solution to the mouse ear 2 hours after a single dose of the tested extracts. The study indicated strong anti-inflammatory activity of the acetone extract in a manner similar to the reference $1 \%$ hydrocortisone ointment. However, the activity of the ethanolic extract was weaker than the reference [51].

\section{Thyroid gland disorders}

The thyroid gland is an essential part of the human endocrine system and directly involved in proper organism development and growth, as well as adaptation to changing environmental factors. Two thyroid hormones, triiodothyronine (T3) and thyroxine (T4), are partially composed of iodine and are mainly responsible for the regulation of cellular metabolism. Their narrow range of serum concentrations are controlled by the thyrotropin-releasing hormone (TRH) released from the hypothalamus and thereafter by the anterior pituitary hormone thyrotropin (TSH) [52].
Thyroid gland disorders can be classified by the characterization of thyroid tissue, including euthyroidism, hyperthyroidism, hypothyroidism, thyroid-associated ophthalmopathy, and abnormal thyroid parameters without thyroid diseases. Euthyroidism disorders are characterized by the normal production of thyroid hormones and their normal levels in the serum. This group includes euthyroid goiter, thyroid tumors, and thyroiditis. However, the overproduction of thyroid hormones leads to primary hyperthyroidism, which can be caused mainly by diffuse hyperthyroid goiter, Graves' disease. However, secondary hyperthyroidism occurs with elevated or inappropriately normal TSH levels due to pituitary disorders and iodine-induced hyperthyroidism, among others. Similarly, hypothyroidism can be divided into primary and secondary hypothyroidism with the manifestation of decreased thyroid hormone production. Primary hypothyroidism includes adult iatrogenic and iodine deficiency hypothyroidism, diffuse and nodular goiter, and neonatal congenital hypothyroidism. Secondary hypothyroidism occurs mainly due to disorders of the hypothalamic-pituitary axis $[53,54]$.

Unfortunately, thyroid gland disorders are principally connected with an inadequate intake of iodine from the diet, with approximately one-third of the world's population living in iodine deficient areas, which leads to cognitive impairment in infants and children. The prevalence of overt hypothyroidism in Europe ranges from 0.2 to $5.3 \%$ [55]. Therefore, the European Food Safety Authority (EFSA) and the WHO, together with the United Nations Children's Fund (UNICEF) and International Council for the Control of lodine Deficiency Disorders (ICCIDD), derived values for adequate intake and the recommended dietary allowance for iodine as $150 \mu \mathrm{g} /$ day for adults, which increases during pregnancy and lactation to a value of $200-250 \mu \mathrm{g} /$ day $[56,57]$. On the other hand, in areas with high iodine intake, a considerable number of thyroid disorders are presumably due to hyperthyroidism and autoimmune thyroiditis. A meta-analysis of European studies revealed a mean prevalence rate of overt hyperthyroidism of $0.75 \%$ [58].

Despite the great advances in thyroid disorder therapy, the usage of phytomedicines still offers fewer side effects than synthetic drugs. However, phytomedicines can be considered a complementary part of comprehensive therapy to treat various thyroid gland disorders. Several species have traditionally been used throughout Europe, Asia, and North America to reduce hyperthyroidism symptoms. Particularly, herbal medicines such as gypsywort, bugleweed, water horehound (Lycopus europaeus L., Lycopus virginicus L., Lycopus americanus Muhl. ex W.P.C. Barton, Lamiaceae, respectively), lemon balm (Melissa officinalis L., Lamiaceae), and western gromwell and European gromwell (Lithospermum ruderale Douglas ex. Lehm. and Lithospermum officinale L., Boraginaceae, respectively) exert beneficial effects to reduce hyperthyroid symptoms, as found during in vitro and in vivo studies. The possible mechanism could be complex, including processes such as reducing TSH formation and its binding to thyroid follicles, decreasing peripheral deiodination of $\mathrm{T} 4$, and/or inhibiting the binding of Graves' disease antibodies to thyroid tissue $[59,60]$. However, the herbal medicines administered to treat hypothyroidism mainly involve the supplementation of iodine. The most widely used herbal medicine is bladderwrack (Fucus vesiculosus L., Fucaceae), which is 
traditionally used in folk medicine and contains high quantities of iodine, approximately $50 \mathrm{\mu g} / \mathrm{g}$ dried mass. Hence, bladderwrack has been evaluated by the Committee on Herbal Medicinal Products (HMPC) of the European Medicines Agency (EMA), which established that an upper daily limit of iodine intake for bladderwrack should not exceed $400 \mu \mathrm{g} /$ day [61]. Moreover, several other phytomedicines, such as ashwagandha (Withania somnifera (L.) Dunal, Solanaceae), gotu kola (Centella asiatica (L.) Urb., Apiaceae), and guggul (Commiphora mukul (Hook. ex Stocks) Engl., Burseraceae), have been shown to efficiently treat hypothyroidism; however, biological studies are very limited [62].

Thyrotropic activity of Potentilla alba extracts

(roots and rhizomes) - in vivo studies

Recently, Abdreshov et al. (2021) reported the influence of Vozrozhdenie plus balm (a preparation containing iodine, starch, ascorbic acid, sodium chloride, glycerine, and gelatine) and a $P$. alba root extract combination on the condition of adrenergic innervation of the thyroid gland, thyroid blood vessels, lymph nodes, and lymphatic vessels in an induced hypothyroidism rat model. The specific histochemical fluorescence microscopy method to visualize catecholamines was used to observe changes in thyroid tissue. This analysis demonstrated that the investigated mixture positively affected the restoration of nerve contours and increased catecholamine concentrations in thyroid tissue and the surrounding lymphatic vessels and nodes. However, the authors underlined that the histological changes after treatment were more marked for the lymphatic system than for the thyroid gland tissue [63]. Moreover, the $\mathrm{CCl}_{4}$ extract rich in triterpenes from $P$. alba whole root segments transformed by Agrobacterium rhizogenes exhibited a reduction in thyroxine levels in the rat thyroid gland, thus protecting the gland from the damage induced by $y$-ray irradiation [64]. Additionally, an extract prepared from the root and rhizomes of $P$. alba was tested in rats with experimental hypothyroidism. Application of the extract raised the levels of the thyroid hormones (T3 and T4 by 34 and 30\%, respectively) [65].

\section{Thyrotropic activity of Potentilla alba extracts (roots and rhizomes) - studies in humans}

The first publication on the thyrotropic activity of white cinquefoil dates from 1975 [13]. White cinquefoil (roots and rhizomes) is currently used in traditional medicine throughout Eastern Europe either alone or as a part of comprehensive therapy against thyroid gland impairments [6]. Based on those reports, several clinical trials have been performed to evaluate the validity and clinical efficacy of the $P$. alba rhizome extracts. In 2012, three independent clinical trials were performed with the same preparation. During the first trial, 55 patients with diagnosed hyperthyroidism, chronic thyroiditis, and diffuse nontoxic goiter during the 6-month trial were treated with a $P$. alba preparation containing $300 \mathrm{mg}$ of an extract twice a day. It was found that this treatment reduced thyroid size and normalized thyroid function, decreased serum antibody levels against thyrotropin receptor (AB-r TSH), and shortened the time needed to stabilize TSH serum levels [66]. In the second study, 77 patients with mixed diffuse and benign goiter divided into a control group and an herbal treatment group were enrolled. The patients in the control group received levothyroxine or thyrostatic therapy, while the treatment group also received a P. alba dry rhizome extract twice a day containing 300 mg per capsule for 2 consecutive months. Compared to control therapy, the extract significantly decreased somatic symptoms of hypo- and hyperthyroidism. Significant changes in nodule volume were also observed [67]. Additionally, in another study, the clinical efficacy of a $P$. alba rhizome extract ( $300 \mathrm{mg}, 2$ capsules per day) added to the basic treatment was evaluated according to international guidelines in 46 patients with toxic goiter. Three months of treatment improved the structure of the thyroid gland, significantly increased thyroid-stimulating hormone, and reduced AB-r TSH levels [68]. A further multicenter clinical study conducted in Ukraine assessed the influence of $P$. alba rhizome extract on thyroid gland volumes. In brief, 1107 patients with autoimmune thyroiditis, nodular goiter, or diffuse nontoxic goiter were enrolled. Monotherapy with a dry rhizome extract at a dose of 300 mg was applied twice a day for 6 months. Notably, the preparation decreased the volume of the thyroid gland by a minimum of $15 \%$ in patients with all investigated impairments. These results showed a significant increase with a higher initial gland volume [69]. Moreover, oral administration of the $P$. alba dry rhizome extract to pediatric patients resulted in a decrease in thyroid size and a normalization of thyroid function [70]. In another clinical trial, the efficacy of a $P$. alba extract (roots and rhizomes) was investigated in 100 patients with subclinical autoimmune thyroiditis, i.e., 74 patients (group 1) had subclinical hypothyroidism (characterized by an elevated TSH level with a normal free thyroxine level), and 26 patients (group 2) had subclinical hyperthyroidism (characterized by a low or undetectable TSH level with a normal serum free thyroxine level). All patients received $300 \mathrm{mg}$ of the extract twice a day for 6 months. At the end of the study, there was a normalization of TSH levels in both group 1 and group 2 accompanied by an improvement in general well-being. In both study groups, a significant decrease in the volume of the thyroid gland and improvement in the morphological structure of the thyroid tissue were observed [71].

Recently, one study described the efficiency and safety of the complex herbal formula Tireoclean, containing P. alba rhizome extract, black chokeberry fruit, redhaw hawthorn, and sodium selenite. A total of 60 patients with chronic autoimmune thyroiditis were enrolled equally in the control and treatment groups. The authors found that a 3-month treatment with the addition of the abovementioned preparation to a complex therapy had a significant influence on the TSH and free thyroxine levels in only the subgroup with subcompensated hypothyroidism, with values of $5.88 \pm 0.56 \mu \mathrm{U} / \mathrm{mL}$ and $1.09 \pm 0.11 \mathrm{pg} / \mathrm{mL}$ before treatment and $4.49 \pm 0.38 \mu \mathrm{U} / \mathrm{mL}$ and $1.21 \pm 0.11 \mathrm{pg} / \mathrm{mL}$ after treatment for TSH and free thyroxine, respectively. However, the tested preparation had no influence on the thyroid gland volume [72]. More interestingly, in another study, a multicomponent phytopreparation (containing $80 \mathrm{mg}$ of an extract of $P$. alba underground parts and other extracts from underground parts of species such as Filipendula vulgaris, Genista tinctoria, and Paeonia anomala, as well as Gemmae betulae extract, Arthrospira, and a leaf extract from Corulus sp.) was administered to elderly women working in chemical factories suffering from cardiovascular and hypothyroidism disorders. This extract combination improved the cardiological, endo- 
crinological, and gastroenterological symptoms of the patients [73].

\section{Toxicity}

Despite the wide usage of white cinquefoil preparations in medicine, the full toxicological profile has not been fully explored through studies in humans due to ethical reasons and economic costs. However, animal rodent models are an acceptable alternative to assess the toxicological potential of herbal formulas. Therefore, there is a need to investigate the safety profile of $P$. alba due to its widespread usage. For the aerial parts of $P$. alba, an $L_{50}$ value of $2359.9 \mathrm{mg} / \mathrm{kg}$ b.w. was deduced based on acute toxicity testing with mice in the dose range of $1000-4000 \mathrm{mg} / \mathrm{kg} \mathrm{b.} \mathrm{w.} \mathrm{Ad-}$ ministration of $239 \mathrm{mg} / \mathrm{kg}$ b. w. (i.e., $1 / 10$ of the $L D_{50}$ ) in a chronic 3-month toxicity study in rats showed no negative impact on the laboratory animals, i.e., no deaths, no changes in consumption and intake of water, and no changes to the hair. Based on these results, the authors classified the aerial part of $P$. alba as virtually nontoxic according to the Organisation for Economic Co-operation and Development (OECD) classification [74]. Acute and chronic toxicity of a rhizome extract of $P$. alba was evaluated in mice and rats. It was found that single intraperitoneal and 3-month chronic administration did not cause toxicity or mortality in the tested rodents $[75,76]$. For an extract prepared from the underground parts of $P$. alba with a mixture of ethanol and water, an $\mathrm{LD}_{50}$ value of $6500 \mathrm{mg} / \mathrm{kg} \mathrm{b.w.} \mathrm{was} \mathrm{determined} \mathrm{in} \mathrm{male} \mathrm{and}$ female rats [33].

Immunotoxicity studies revealed that the dry rhizome extract from white cinquefoil at a dose of $50 \mathrm{mg} / \mathrm{kg}$ b. w. had no negative impact on humoral, cellular, or macrophage immunity in the two mouse breeds. Furthermore, a study revealed that $P$. alba rhizome extract at a dose of $3 \mathrm{mg} / \mathrm{kg}$ b. w. administered to albino guinea pigs stimulated the primary humoral response. Moreover, the tested sample had no sensitizing effect in either systemic or active skin anaphylaxis or delayed hypersensitivity [77]. Moreover, the application of an extract of white cinquefoil (underground parts) to mice treated with the cytostatic agent azathioprine led to a decrease in the suppressive action of the cytostatic agent on antibody formation and the indirect cellular immune reaction, thus demonstrating the immunomodulatory effects of the extract [78]. Unfortunately, white cinquefoil preparations administered orally have a negative impact on the ante- and postnatal rat offspring periods of development, resulting in retardment of the ossification process occurring in the cartilaginous part of bones of 20-day-old fetuses [79]. Furthermore, the same extract had an impact on the male rat reproductive system, resulting in a decrease in sperm motility and Leydig cell nucleus diameters and an increase in pyknotic nuclei and a higher number of pathological spermatozoa. Despite these observations, the authors concluded that the extract did not significantly affect rodent fertility or offspring development after healthy female impregnation [80].

\section{Conclusion/Perspectives}

Documented evidence suggests that $P$. alba is a rich source of polyphenolics with a broad spectrum of activities. Studies in hu- mans support the ethnomedical use of $P$. alba as a monotherapy or as a part of a comprehensive therapy for different thyroid gland impairments. However, despite promising results, the underlying mechanism of action, bioavailability, and pharmacokinetics of the main active compounds are still unknown. Therefore, further studies should focus deeply on these aspects to fully reveal their potential, especially clinical studies, and to further substantiate the use of $P$. alba extracts to treat thyroid disorders. Notably, the other problem with the use of $P$. alba extracts is its gradually ending resource in its natural habitat. The highest demand for the underground parts of $P$. alba would result in the extinction of this species in the near future. However, several studies have been conducted to develop efficient renewable raw plant materials with similar elemental and secondary metabolite compositions.

\section{Contributors' Statement}

Conception and design of the study: D. Augustynowicz, M. Tomczyk; data collection: D. Augustynowicz, M. Podolak; analysis and interpretation of the data: D. Augustynowicz, M. Podolak, K.P. Latté, M. Tomczyk; drafting the manuscript: D. Augustynowicz, M. Podolak, M. Tomczyk; critical revision of the manuscript: K.P. Latté. All authors have read and agreed to the published version of the manuscript.

\section{Conflict of Interest}

The authors declare that they have no conflict of interest.

\section{References}

[1] Philipp M, Kohnen R, Hiller KO. Hypericum extract versus imipramine or placebo in patients with moderate depression: randomised multicentre study of treatment for eight weeks. BMJ 1999; 319: 1534-1538

[2] Hasani-Ranjbar S, Nayebi N, Moradi L, Mehri A, Larijani B, Abdollahi M. The efficacy and safety of herbal medicines used in the treatment of hyperlipidemia; a systematic review. Curr Pharm Des 2010; 16: 2935-2947

[3] Moreira DL, Teixeira SS, Monteiro MHD, De-Oliveira ACAX, Paumgartten FJR. Traditional use and safety of herbal medicines. Rev Bras Farmacogn 2014; 24: 248-257

[4] Singh D, Gupta R, Saraf SA. Herbs-are they safe enough? an overview. Crit Rev Food Sci Nutr 2012; 52: 876-898

[5] Augustynowicz D, Latte KP, Tomczyk M. Recent phytochemical and pharmacological advances in the genus Potentilla L. sensu lato - An update covering the period from 2009 to 2020. J Ethnopharmacol 2021; 266: 113412

[6] Pankiv VI. Thyrotoxicosis syndrome: new clinical opportunities for the correction of thyroid dysfunction. Internat J Endocrinol 2020; 16: 58-62

[7] Semkina OA, Kachalina TV, Malysheva NA, Sagaradze VA, Burova AE, Djavakhyan MA. Technological aspects of the development of the tablet dry extract Potentilla alba L. Probl Biol Med Pharm Chem 2018; 21: 9-14

[8] Linné C. Spedies Plantarum. Holmiæ, Stockholm: Impensis Laurenti Salvii; 1753

[9] Plants of the World. Potentilla alba L. Accessed July 28, 2021 at: http://www.plantsoftheworldonline.org/taxon/urn:Isid:ipni.org:names: 324728-2

[10] Tomczyk M, Latte KP. Potentilla - a review of its phytochemical and pharmacological profile. J Ethnopharmacol 2009; 122: 184-204 
[11] Indreica A. On the occurence in Romania of Potentillo albae-Quercetum petraeae Libbert 1933 association. Not Bot Hort Agrobot Cluj 2011; 39: 297-306

[12] Metzing D, Hofbauer N, Ludwig G, Matzke-Hajek G. Rote Liste gefährdeter Tiere, Pflanzen und Pilze Deutschlands. Band 7: Pflanzen. Naturschutz und Biologische Vielfalt. Münster: Landwirtschaftsverlag; 2018

[13] Smyk GK, Krivenko VV. White cinquefoil, an effective agent for treating thyroid gland diseases. Farm Zh (Kiev) 1975; 2: 58-62

[14] Samatadze TE, Zoshchuk SA, Khomik AS, Amosova AV, Svistunova NY, Suslina SN, Hazieva FM, Yurkevich OY, Muravenko OV. Molecular cytogenetic characterization, leaf anatomy and ultrastructure of the medicinal plant Potentilla alba L. Genet Resour Crop Evol 2018; 65: 1637-1647

[15] Bogacheva NG, Meshkov Al, Konyaeva EA, Alent'eva OG. Pharmacognostic study of the rhizomes and the roots Potentilla alba L. Prob Biol Med Pharm Chem 2016; 1: 28-32

[16] Fuchs L. New Kreüterbuch. Basel: Reprint Taschen; 1543

[17] Tabernaemontanus JT. Neu vollkommen Kräuter-Buch: Darinnen über 3000. Kräuter, mit schönen und kunstlichen Figuren, auch deren Unterscheid und Würckung. Basel: Johann Ludwig König und Johann Brandmyllern; 1664

[18] Tikhomirova LI, Kechaykin AA, Shmakov AI, Alexandrova OV. An effective way to carry out mass in vitro propagation of Potentilla alba L. Biol Bull Bogdan Chmelnitskiy Melitopol State Pedagog Univ 2016; 6: 433-444

[19] Bashilov AV. Use of Potentilla alba L. as a raw pharmaceutical material in Republic of Belarus. Ekol Vestn Nauchno Prakt Zh 2010; 3: 85-88

[20] Shishlo MS. Description of some species of the genus Potentilla sp. World Sci 2016; 2: 5-8

[21] Kaminskii AV, Kiseleva IA, Teplaia EV. Clinical application of Potentilla alba for prevention and treatment of thyroid gland pathologies. Lik Sprava 2013; 8: 99-108

[22] Shikov AN, Lazukina MA, Pozharitskaya ON, Makarova MN, Golubeva OV, Makarov VG, Djachuk GI. Pharmacological evaluation of Potentilla alba L. in mice: adaptogenic and central nervous system effects. Pharm Biol 2011; 49: 1023-1028

[23] Shikov AN, Narkevich IA, Flisyuk EV, Luzhanin VG, Pozharitskaya ON. Medicinal plants from the 14th edition of the Russian Pharmacopoeia, recent updates. J Ethnopharmacol 2021; 268: 113685

[24] Ossipov VI, Polyakov NA, Khazieva FM, Sidelnikov AN. Proanthocyanidins in the roots and rhizomes of Potentilla alba (Rosaceae). Rastit Resur 2017; 53: 114-125

[25] Polyakov NA, Ossipov VI. Comparative study of the contents of main classes of phenolic compounds in roots and rhizomes of Potentilla alba, Potentilla recta and Potentilla anserina. Prob Biol Med Pharm Chem 2019; 22: 9-14

[26] Melik-Gusseinov V, Tkhamokova F. Identification of the phenol compounds in the roots of Potentilla alba L. introduced to the North Caucasus. Bull MSRU Ser Nat Sci 2012; 1: 49-52

[27] Polyakov NA, Hazieva FM, Meshkov AI, Korotkikh IN, Ossipov VI. The composition and content of proanthocyanidins of white cinquefoil roots (Potentilla alba). In: Materials of the International Symposium Phenolic Compounds: Fundamental and Applied Aspects, Moscow, Russia, May 14th-19th, 2018

[28] Kosman VM, Faustova NM, Pozharitskaya ON, Shikov AN, Makarov VG. Accumulation of biologically active compounds in the underground parts and composition of Potentilla alba L. after various cultivation terms. Russ J Bioorg Chem 2013; 2: 139-146

[29] Matkowski A, Świąder K, Ślusarczyk S, Jezierska-Domaradzka A, Oszmiański J. Free radical scavenging activity of extracts obtained from cultivated plants of Potentilla alba and Waldsteinia geoides L. Herba Pol 2006; 52: 91-97

[30] Kowalik K, Paduch R, Strawa JW, Wiater A, Wlizlo K, Wasko A, Wertel I, Pawlowska A, Tomczykowa M, Tomczyk M. Potentilla alba extracts affect the viability and proliferation of non-cancerous and cancerous colon human epithelial cells. Molecules 2020; 25: 3080

[31] Bazarnova NG, Tikhomirova LI, Frolova NS, Mikushina IV. Isolation and analysis of extractives from white cinquefoil (Potentilla alba L.) grown under different conditions. Russ J Bioorganic Chem 2017; 43: 752-759

[32] Bate-Smith EC. Chromatography and taxonomy in the Rosaceae with the special reference to Potentilla and Prunus. Bot J Linn Soc 1961; 58: 39-54

[33] Sherieva FK. Pharmacognostic study of white Cinquefoil - Potentilla alba L., introduced in the North Caucasus [dissertation]. Pyatigorsk: Volgograd State Medical University; 2015

[34] Kovaleva AM, Abdulkafarova ER. Phenolic compounds from Potentillo alba. Chem Nat Compd 2011; 47: 290-291

[35] Kitaeva MV, Kot AA, Spiridovich EV. The comparative analysis of species Potentilla L. - Potentilla alba L., Potentilla recta L., Potentilla rupestris L. as the producers of biologically active substances by secondary metabolities in the Central region agroclimatic conditions of the Republic of Belarus. B Bryansk RBS 2014; 1: 67-70

[36] Oszmianski J, Wojdylo A, Lamer-Zarawska E, Swiader K. Antioxidant tannins from Rosaceae plant roots. Food Chem 2007; 100: 579-583

[37] Khisyamova DM. Comparative Study of certain Representatives of the Genus Potentilla L. [dissertation]. Samara: Samara State Medical University; 2017

[38] Gritsenko OM, Smik GK. Phytochemical study of Potentilla alba. Farm Zh (Kiev) 1977; 1: 88-89

[39] Neilla HS, Kovalyova AM, Abdulkafarova ER, Ochkur OV. Fatty acids of Potentilla alba L. lipophilic extracts. Conference "Topical Issues of New Drugs Development”, Kharkiv, Ukraine, April 23rd, 2015

[40] Kovalyova AM, Abdulkafarova ER, Ilyina TB. Research of fatty acids of herb white bloodroot (Potentilla alba L.). GISAP Med Sci Pharmacol 2013; 1: 66-67

[41] Świeżewska E, Chojnacki T. The occurrence of unique, long-chain polyprenols in the leaves of Potentilla species. Acta Biochim Pol 1989; 36: $143-158$

[42] Tikhomirova LI, Bazarnova NG, Sysoeva AV, Shcherbakova LV. Phytochemical analysis of biotechnological raw materials of representatives of the genus Potentilla L. Russ J Bioorganic Chem 2019; 45: 942-949

[43] Melik-Gusseinov V, Tkhamokova F, Shylnikov D. Prospects of cultivating Potentilla alba L. in the Northern Caucasus. Bull MSRU Geogr Environ Living Syst 2013; 2: 49-52

[44] Torikov VE, Meshkov II. Introduction, ecology, cultivation and element composition of cinquefoil (Potentilla alba L.) in the Bryansk region. Bull Bryansk State Agric Acad 2016; 2: 15-19

[45] Damien Dorman HJ, Shikov AN, Pozharitskaya ON, Hiltunen R. Antioxidant and pro-oxidant evaluation of a Potentilla alba L. rhizome extract. Chem Biodivers 2011; 8: 1344-1356

[46] Grujić-Vasić ], Pilipović S, Bosnić T, Redžić S. Antimicrobial activity of different extracts from rhizome and root of Potentilla erecta L. Raeusche and Potentilla alba L. Rosaceae. Acta Med Acad 2006; 35: 9-14

[47] Yang Y, Asyakina L, Babich O, Dyshluk L, Sukhikh S, Popov A, Kostyushina N. Physicochemical properties and biological activity of extracts of dried biomass of callus and suspension cells and in vitro root cultures. Food Process Tech Technol 2020; 50: 480-492

[48] Espinosa-Leal CA, Puente-Garza CA, Garcia-Lara S. In vitro plant tissue culture: means for production of biological active compounds. Planta 2018; 248: 1-18

[49] Dubinina A, Letuta T, Frolova T, Savinova H, Bolshakova G, Novikova V. Research of toxicity of chitosan-based film-forming compositions. Technol Audit Prod Res 2017; 6: 39-46

[50] Tikhomirova LI, Zaripova AA. Development of biotechnology for cultivating Potentilla L. plant material with antivirus and antibacterial activity. IOP Conf Ser Mater Sci Eng 2020; 941: 012030 
[51] Pilipovic S, Grujic-Vasic J, Ibrulj A, Redzic S, Bosnic T. Antiinflammatory effect of rhizome and root of Potentilla erecta (L.) Raeuschel and Potentilla alba L. (Rosaceae). Book of Abstracts. Joint Meeting of the Society of Medicinal Plant Research, Florence; August 21st-25th. Vienna: Society of Medicinal Plant Research; 2005: P164, 192

[52] Stathatos N. Anatomy and Physiology of the thyroid Gland. In: Luster M, Duntas LH, Wartofsky L, eds. The Thyroid and its Diseases. Cham: Springer; 2019: 3-12

[53] Duntas LH, Tseleni-Balafouta S. Classification of thyroid Diseases. In: Luster M, Duntas LH, Wartofsky L, eds. The Thyroid and its Diseases. Cham: Springer; 2019: 87-99

[54] Monaco F. Classification of thyroid diseases: suggestions for a revision. J Clin Endocrinol Metab 2003; 88: 1428-1432

[55] Taylor PN, Albrecht D, Scholz A, Gutierrez-Buey G, Lazarus JH, Dayan CM, Okosieme OE. Global epidemiology of hyperthyroidism and hypothyroidism. Nat Rev Endocrinol 2018; 14: 301-316

[56] EFSA Panel on Dietetic Products, Nutrition and Allergies (NDA). Scientific opinion on dietary reference values for iodine. EFSA J 2014; 12: 3660

[57] World Health Organization UCsF, International Council for the Control of Iodine Deficiency Disorders. Assessment of Iodine Deficiency Disorders and Monitoring their Elimination: a Guide for Programme Managers, 3rd ed. Geneva: World Health Organization; 2007

[58] Garmendia Madariaga A, Santos Palacios S, Guillén-Grima F, Galofré JC. The incidence and prevalence of thyroid dysfunction in Europe: a metaanalysis. J Clin Endocrinol Metab 2014; 99: 923-931

[59] Auf'mkolk M, Ingbar JC, Kubota K, Amir SM, Ingbar SH. Extracts and auto-oxidized constituents of certain plants inhibit the receptor-binding and the biological activity of Graves' immunoglobulins. Endocrinology 1985; 116: 1687-1693

[60] Al-Snafi AE. A review on Lycopus europaeus: a potential medicinal plant. IOSR J Pharm 2019; 9: 80-88

[61] European Medicines Agency (EMA). Bladderwrack. EMA/661584/2016. Accessed July 28, 2021 at: https://www.ema.europa.eu/en/medicines/ herbal/fucus-vesiculosus-thallus

[62] Yarnell E, Abascal K. Botanical medicine for thyroid regulation. Altern Complement Ther 2006; 12: 107-112

[63] Abdreshov SN, Demchenko GA, Mamataeva AT, Atanbaeva GK, Mankibaeva SA, Akhmetbaeva NA, Kozhaniyazova UN, Nauryzbai UB. Condition of adrenergic innervation apparatus of the thyroid gland, blood and lymph vessels and lymphonosis during the hypothyrosis correction. Bull Exp Biol Med 2021; 171: 253-258

[64] Kovalenko PG, Antonjuk VP, Maliuta SS. Secondary metabolites synthesis in transformed cells of Glycyrrhiza glabra L. and Potentilla alba L. as producents of radioprotective compounds. Ukr Bioorg Acta 2004; 1-2: 1322

[65] Arkhipova EV, Vodopyanova AM, Kolhir VK. The influence of dry extract of cinquefoil white on current experimental hypothyroidism. Acta Biomed Sci 2011; 1: 116-118
[66] Kiselëva IA, Tëplaia EV, Kaminskiľ AV. Application of herbal medicine Alba $^{\circledR}$ in treatment of patients with the pathology of thyroid. Lik Sprava 2012; 8: 116-119

[67] Kvacheniuk AN, Kvacheniuk EL. The use of phytotherapy for treatment of thyroid diseases. Lik Sprava 2012; 3-4: 99-104

[68] Pankiv VI. Phytotheraphy in complex treatment of patients with toxic goiter. Clin Thyroidol 2012; 2: 114-117

[69] Pankiv VI, Gurianov VG, Petrovska LR. Dynamics of thyroid gland sizes in patients with diffuse and nodular goiter, autoimmune thyroiditis during monotherapy by Alba ${ }^{\circledR}$ preparation in different regions of Ukraine. Internat J Endocrinol 2017; 13: 526-535

[70] Turchaninova LI. Experience of using phytopreparation Alba (root extract of the Potentilla alba) in complex treatment of thyroid pathology in children and adolescents. Lik Sprava 2014; 3-4: 125-129

[71] Chernyavska IV, Ramanov IP, Dorosh EG. Approaches to the treatment of subclinical forms of thyroid pathology. Probl Endocr Pathol 2017; 60: 49-56

[72] Hotsko MJ, Serhiyenko VO, Bobrovych IV, Makarovska RJ, Serhiyenko OO. The experience of application of complex fitodrug containing Potentilla alba L. in patients with chronic autoimmune thyroiditis. Bull Probl Biol Med 2020; 4: 83

[73] Voloshin Al, Ilashchuk TA, Voloshina LA, Pankiv IV, Yuzvenko VS. The probability of the influence of professional chemical factors on the development of hypothyroidism and other lesions of the human body. Int J Endocrinol 2020; 16: 227-230

[74] Khishova OM, Shimko OM, Avdavchenok VD. The study of the safe use of Potentilla alba herb. Vestn VGMU 2016; 15: 92-98

[75] Bortnikova VV, Babenko AN, Kuzina OS, Radimich Al. Study of acute toxicity of dry extract of Potentilla alba L. Probl Biol Med Pharm Chem 2019; 22: 51-54

[76] Arkhipova EV, Khobrakova VB, Nikolaev SM. The study of immunotoxicity of the dry extract from Potentilla alba L. Sib Med J (Irkutsk) 2015; 3: $108-110$

[77] Bortnikova VV, Krepkova LV, Mizina PG, Guskova TA. Investigation of immunotoxicity and allergenic properties of dry extract of Potentilla alba $\mathrm{L}$. Toxicol Rev 2018; 4: 15-19

[78] Khobrakova VB, Arkhipova EV, Vodopyanova AV. The influence of the dry extract from Potentilla alba $\mathrm{L}$. on the state of cellular and humoral chains of the immune response. Acta Biomed Sci 2011; 1: 195-197

[79] Savinova TV, Krepkova LV, Bortnikova VV. Influence of Potentilla alba L. on the development of offspring rats in the antenatal and postnatal periods of development. Probl Biol Med Pharm Chem 2018; 21: 43-48

[80] Krepkova LV, Bortnikova VV, Babenko AN, Mizina PG, Mkhitarov VA, Job $\mathrm{KM}$, Sherwin CM, Enioutina EY. Effects of a new thyrotropic drug isolated from Potentilla alba on the male reproductive system of rats and offspring development. BMC Complement Med Ther 2021; 21: 31 